\title{
Uso de coberturas comestíveis a base de fécula de mandioca associado à refrigeração na qualidade pós-colheita de goiaba paluma
}

\section{Use of edible manioc starch-based toppings associated with refrigeration in the post- harvest quality of guava paluma}

\author{
Luana Muniz de Oliveira ${ }^{1 *}$, Marília Hortência Batista Silva Rodrigues ${ }^{2}$, Marinês Pereira Bomfim ${ }^{3}$, Valéria Fernandes de \\ Oliveira Sousa ${ }^{4}$, Rodolfo Wagner de Paiva Trigueiro ${ }^{5}$, Edinete Nunes de Melo ${ }^{6}$
}

\begin{abstract}
Resumo: Objetivou-se avaliar o comportamento pós-colheita dos frutos de goiabas paluma armazenados em temperatura refrigerada a $12{ }^{\circ} \mathrm{C}$ sob diferentes concentrações de coberturas comestíveis a base de fécula de mandioca. Os frutos foram obtidos de um pomar comercial localizado na comunidade de Várzeas no município de Sousa Paraíba, sendo transportadas para o Laboratório de Tecnologia de Alimentos da Universidade Federal de Campina Grande campus Pombal, onde foi conduzido o experimento, realizado em parcelas subdividas em esquema fatorial 4x6 sendo quatro formulações de coberturas $(0,1,2$, e $3 \%$ de fécula de mandioca), e seis tempos de armazenamento $(0,3,6,9,12$ e 15 dias $)$. Foram realizadas as análises de perda de massa; coloração da casca; firmeza do fruto; $\mathrm{pH}$; acidez titulável; sólidos solúveis; razão sólidos solúveis e acidez titulável, ácido ascórbico. Nas condições do experimento, os frutos armazenados sob refrigeração apresentaram vida útil de 15 dias. A fécula de mandioca associado com a refrigeração, retardou o amadurecimento dos frutos, principalmente nos frutos revestidos com $2 \%$ da fécula de mandioca, proporcionando um melhor aspecto e conservação, tornando o fruto mais atraente visualmente.
\end{abstract}

Palavras-chave: Armazenamento; Conservação; Psidium guajava L.; Vida útil.

Abstract: The objective of this study was to evaluate the post-harvest behavior of 'paluma' guava fruits stored at refrigerated temperature at $12^{\circ} \mathrm{C}$ and under different concentrations of edible manioc starch based coatings. The fruits were obtained from a commercial orchard located in the community of Várzeas in the municipality of Sousa Paraíba, being transported to the Food Technology Laboratory of the Federal University of Campina Grande, Pombal campus, where the experiment was carried out in subdivide plots in a factorial scheme $(0,1,2$, and $3 \%$ cassava starch), and six storage times $(0,3,6,9,12$ and 15 days). The mass loss analyzes were performed; shell coloring; firmness of the fruit; $\mathrm{pH}$; titratable acidity; soluble solids; soluble solids ratio and titratable acidity, ascorbic acid. Under the conditions of the experiment, the fruits stored under refrigeration had a shelf life of 15 days. The manioc starch associated with refrigeration delayed fruit ripening, especially in fruits coated with $2 \%$ cassava starch, providing a better appearance and conservation, making the fruit more attractive visually.

Key words: Storage; Conservation; Psidium guajava, L; Lifespan.

\footnotetext{
*Autor para correspondência

Recebido para publicação em 07/04/2017; aprovado em 25/06/2017

${ }^{1}$ Mestranda em Horticultura Tropical, Universidade Federal de Campina Grande, Pombal-PB. E-mail: luanamuniz43@hotmail.com

${ }^{2}$ Mestranda em Horticultura Tropical, Universidade Federal de Campina Grande, Pombal-PB. E-mail: marilia_agroecologa@ hotmail.com

${ }^{3}$ Doutora em Agronomia, Horticultura ,Universidade Estadual Paulista, Botucatu -SP. E-mail: mpbfito@gmail.com

${ }^{4}$ Mestranda em Horticultura Tropical, Universidade Federal de Campina Grande, Pombal-PB. E-mail: valeriafernandesbds@gmail.com

${ }^{5}$ Engenheiro Agrônomo. Universidade Federal de Campina Grande, Pombal-PB; E-mail: rodolfo.wpt@hotmail.com

${ }^{6}$ Mestranda em Horticultura Tropical, Universidade Federal de Campina Grande, Pombal-PB. E-mail: ednetmello@hotmail.com
} 


\section{INTRODUÇÃO}

A goiabeira (Psidium guajava, L.) é originária da região tropical do continente americano e foi disseminada para as diferentes regiões do mundo, é uma excelente fruta para o consumo humano, tem grande aceitação no mercado, sendo considerada uma das melhores fontes de vitamina $\mathrm{C}$, além de possuir baixo conteúdo calórico e ótimo potencial antioxidante (GOMES FILHO et al. 2016; DURIGAN et al., 2009). Suas qualidades nutricionais fazem com que a goiaba tenha merecido atenção especial, constitui-se em uma das mais importantes matérias prima para as indústrias de sucos, polpas e néctares, e para o consumo in natura. (SIQUEIRA, 2012).

A goiaba é um fruto climatérico, apresenta altas taxas de transpiração e perda de massa (AZZOLINI et al., 2005). Devido ao intenso metabolismo durante o amadurecimento, esses frutos entram em senescência rapidamente, impedindo o armazenamento por períodos prolongados, e o controle da respiração e transpiração reduz a velocidade das mudanças fisiológicas, aumentando a vida útil (SIQUEIRA et al. 2014).

No Brasil, a produção de frutos com qualidade, objetivando a comercialização dos mesmos como produtos frescos, em mercados cada vez mais exigentes, tem sido destaque na fruticultura (MORGADO et al. 2010). Segundo dados do IBGE (2015) a produção nacional de goiaba foi de $24.103 \mathrm{Kg} / \mathrm{ha}$, concentrando no estado da Paraíba o rendimento de $5.635 \mathrm{Kg} / \mathrm{ha}$.

Nesse sentido, há um crescente interesse pela utilização de novas tecnologias que impeçam a interferência de fatores externos responsáveis pela deterioração rápida dos alimentos (GOMES FILHO et al. 2016). O uso de atmosfera modificada como coberturas comestíveis, mais a redução da temperatura de armazenamento tem sido umas das alternativas viáveis na conservação subjetiva de frutas e hortaliças (LUNGUINHO et al., 2014).

O uso de coberturas comestíveis, na conservação de frutas na condição pós-colheita, tem sido preconizado como uma tecnologia emergente e de grande potencial, principalmente para aplicações sobre frutas de origem tropical, como uva, mamão, manga e goiaba (ASSIS; BRITO, 2014). Existem diversas formulações de cobertura comestível dentre elas a base de fécula de mandioca, quitosana e amido, de acordo com Nunes et al. (2017) a fécula de mandioca além de ser uma matéria prima de baixo custo, apresenta um ótimo custo-benefício, necessitando de estudos para determinação da melhor concentração para cada frutífera.

$\mathrm{O}$ presente trabalho teve por objetivo avaliar o comportamento pós-colheita dos frutos de goiabas paluma armazenadas em temperatura refrigerada a $12{ }^{\circ} \mathrm{C}$ e sob diferentes concentrações de cobertura comestível a base de fécula de mandioca.

\section{MATERIAL E MÉTODOS}

Os frutos foram obtidos de um pomar comercial na comunidade de várzeas no município de Sousa Paraíba. O experimento foi realizado no Laboratório de Tecnologia de Alimentos da Universidade Federal de Campina Grande, campus Pombal (PB), onde procedeu-se uma seleção cuidadosa, descartando aqueles com injúrias ocorridas durante o transporte, em seguida, os frutos foram lavados com solução de detergente neutro a $1 \%$ e, após enxágue, sanitizados com solução de hipoclorito de sódio a 100 ppm de cloro livre por 15 minutos, e enxágue em água corrente.

$\mathrm{O}$ experimento foi realizado em parcelas subdividas em esquema fatorial $4 \times 6$ sendo quatro formulações de fécula de mandioca $(0,1,2$, e $3 \%$, ) e seis tempos de armazenamento $(0$, $3,6,9,12$ e 15 dias) com três repetições. Para o preparo das suspensões de fécula, foram pesadas e diluídas, respectivamente, 5,10 e $15 \%$ de fécula de mandioca em 1 litro de água destilada, sendo as suspensões aquecidas a $70^{\circ} \mathrm{C}$.

Posteriormente, o filme foi resguardado na bancada, para ser resfriado à temperatura ambiente, logo após esse período os frutos foram imersos por 5 minutos nas concentrações, e o excesso de suspensão foi drenado, dispondo-se os frutos em recipientes vazados. Após a secagem, os frutos foram acondicionados em bandejas de isopor e armazenados em câmara do tipo B.O.D. na temperatura refrigerada a $12^{\circ} \mathrm{C}$ e $80 \%$ umidade relativa.

Foram realizadas as análises de perda de massa; firmeza do fruto; coloração da casca; $\mathrm{pH}$; acidez titulável; sólidos solúveis; razão sólidos solúveis e acidez titulável; (Ratio) e ácido ascórbico.

A Perda de massa foi determinada pela diferença da massa inicial dos frutos no dia da colheita e em cada período de avaliação, utilizando balança de precisão $0,01 \mathrm{~g}$, sendo os resultados expressos em porcentagem. Os parâmetros de coloração da casca, luminosidade, ângulo de cor e cromaticidade, foram estabelecidos utilizando-se da metodologia indicada por (PINHEIRO, 2009). Para medição da firmeza foi utilizado um penetrômetro digital de bancada com ponteira de prova de $6,0 \mathrm{~mm}$ e os resultados expressos em Newton.

$\mathrm{O} \mathrm{pH}$ foi determinado diretamente na polpa, em triplicata utilizando um potenciômetro digital com eletrodo de membrana de vidro, calibrado com solução tampão de pH 4,0 e 7,0. A acidez foi determinada em triplicata, utilizando-se $2 \mathrm{~g}$ de polpa, à qual foi homogeneizados e adicionados $45 \mathrm{~mL}$ de água destilada e 3 gotas de fenolftaleína alcoólica a 1\%, em seguida, foi feita a titulação com solução de hidróxido de sódio $\mathrm{NaOH} 0,1 \mathrm{M}$ até mudança de cor para róseo claro, expressando-se os resultados em percentagem (\%) de ácido cítrico. O conteúdo de Sólidos Solúveis foi determinado em triplicata através da polpa, utilizando o refratômetro digital portátil. Os dados foram expressos em porcentagem (\%). A relação SS/ AT foi obtido dividindo-se os valores de sólidos solúveis pelos valores da acidez titulável. O teor de ácido ascórbico foi determinado através de titulação com solução de Tillmans, que se baseia na redução do corante sal sódico de 2,6-dicorofenol indofenol (DFI) por uma solução acida de vitamina $\mathrm{C}$. Inicialmente foi pesado $0,2 \mathrm{~g}$ da amostra e até obtenção de coloração rósea claro permanente, utilizando-se 1,0 mL do suco diluído em 49,0 mL de ácido oxálico $0,5 \%$ e os resultados foram expresso em \% de ácido ascórbico. (INSTITUTO ADOLFO LUTZ, 2008).

Os dados foram submetidos ao teste $\mathrm{F} 5 \%$ de significância, por meio de análise de variância (ANOVA) e regressão. As análises estatísticas forma realizadas no software SISVAR versão 5.6 (FERREIRA, 2011).

\section{RESULTADOS E DISCUSSÃO}

A análise de variância pelo teste de $\mathrm{F}$, a $5 \%$ de significância indicou que houve interação significativa entre as diferentes concentrações de fécula de mandioca em função 
dos tempos de armazenamento de Goiaba paluma para todas as variáveis analisadas.

A perda de massa dos frutos ao longo do tempo do armazenamento pode ser verificada na Figura 1. Independente do uso de cobertura houve perda de massa durante o armazenamento, sendo que os frutos com características de maturação foram registrados aos 15 dias de armazenamento. Em relação às concentrações a menor média foi observada no tratamento que recebeu na concentração de $3 \%$ de fécula de mandioca com massa inicial de $149,24 \mathrm{~g}$ e massa final de $100 \mathrm{~g}$ equivalente a uma perda de 33,04\%. Nas concentrações 0 e $1 \%$ as perdas de massa foram de $31 \%$ e $24,32 \%$ respectivamente entre o início e o final do tempo de armazenamento. Contudo, a concentração de $2 \%$ de fécula de mandioca proporcionou uma menor perda de massa com média inicial de $181,78 \mathrm{~g}$ e final de $160 \mathrm{~g}$ que corresponde à perda de $12 \%$.

Figura 1. Perda de Massa dos frutos de goiaba paluma armazenados sob refrigeração e diferentes concentrações de fécula de mandioca ao longo do tempo de armazenamento.

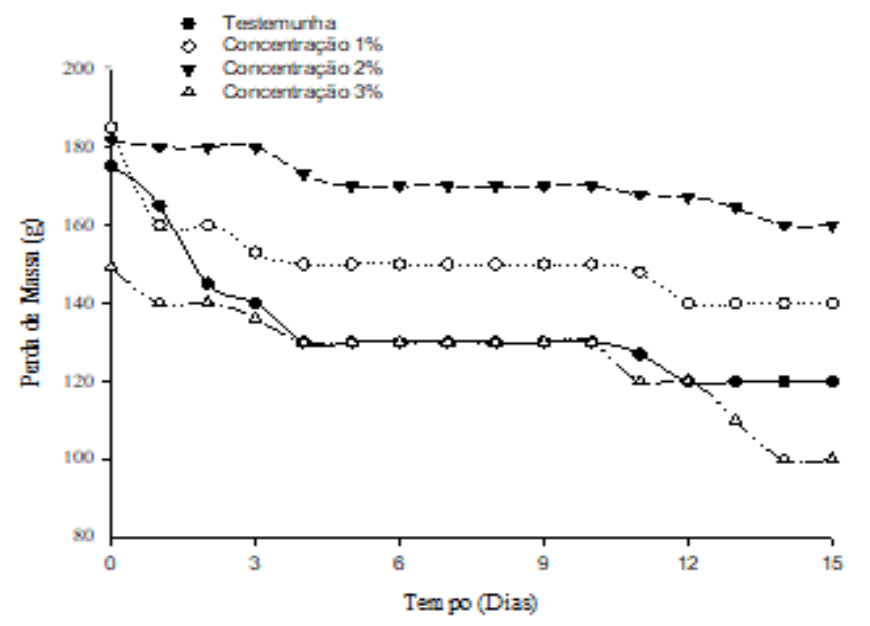

A perda de massa é decorrente de altas taxas de transpiração e respiração causando perda de água nos frutos para o ambiente, logo o revestimento com a concentração de $3 \%$ da fécula permitiu uma maior perda de massa devido à descamação do revestimento ao longo do tempo de armazenamento. Lunguinho et al. (2014) obtiveram resultados semelhantes na utilização de fécula de mandioca e amido de milho na conservação dos frutos de goiaba Paluma, em que frutos sob temperatura de $10^{\circ} \mathrm{C}$, observou-se perda em maior escala para o tratamento na concentração de $3 \%$ tanto para o amido de milho bem como para fécula de mandioca.

Corroborando, Gomes Filho et al. (2016) avaliando a qualidade pós-colheita de goiabas Pedro Sato tratadas com diferentes concentrações de fécula de mandioca associadas a substâncias antifúngicas, observaram perda de massa dos frutos testemunha de aproximadamente $20 \%$ no período de armazenamento, enquanto que nos frutos revestidos com biofilmes em diferentes concentrações com e sem substâncias antifúngicas a perda de massa foi de aproximadamente $10 \%$, sendo que o tratamento que obteve os menores valores foram a fécula de mandioca na concentração de $3 \%$ associada ao extrato de cravo, com valores de $8,87 \%$.

Com relação ao parâmetro da coloração, sabe-se que a luminosidade (coordenada $\mathrm{L}^{*}$ ) da casca ou brilho dos frutos pode variar do zero (preto) a 100 (branco) os frutos, neste estudo, apresentaram luminosidade variando com o tempo de armazenamento e tratamento. Os valores de $\mathrm{L}^{*}$ apresentaram efeito em todos os tempos de armazenamento, com incremento entre os 6 até o 15 dias, além disso, os frutos sem cobertura durante o armazenamento sofreram um processo de amadurecimento mais rápido do que os demais tratamentos, demonstrando mudança de tom para o amarelo (SIQUEIRA et al., 2011).

Contudo, o uso da cobertura na concentração de $2 \%$ de fécula de mandioca proporcionou menor aumento na $\mathrm{L}^{*}$ até o $15^{\circ}$ dia de armazenamento, sendo mais eficiente no retardamento do amadurecimento dos frutos, enquanto que a concentração de $3 \%$ proporcionou valores próximos ao tratamento controle (Figura 2), esse comportamento pode ser explicado pela descamação da película nessa concentração no decorrer do tempo de armazenamento.

Todavia, todos os frutos se encontraram em estádio maduro aos 15 dias de armazenamento, mas sem deterioração no aspecto de vida útil. Forato et al. (2011) relataram que as coberturas com carboxi-metilcelulose retardaram o aparecimento da cor amarela em goiabas, e que os filmes tornaram o fruto mais opaco e retardaram a síntese e degradação dos pigmentos que fazem com que o fruto adquira brilho, retardando o aparecimento de brilho mais acentuado.

Figura 2. Luminosidade dos frutos de goiaba paluma armazenados sob refrigeração e diferentes concentrações de fécula de mandioca ao longo do tempo de armazenamento.

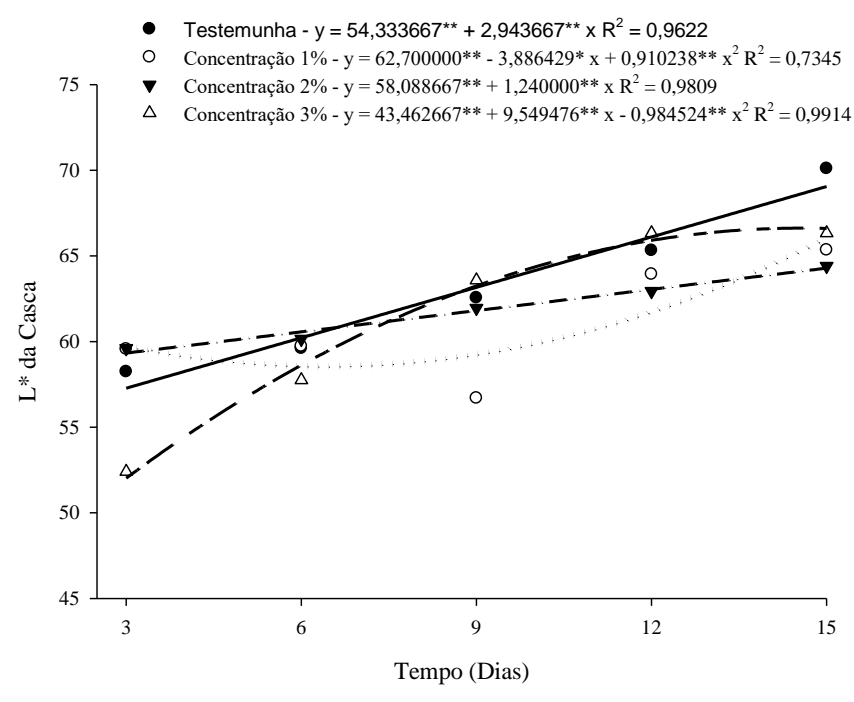

Análises da cromaticidade $\left(\mathrm{C}^{*}\right)$ indicam tendência de aumento linear em todos os tempos de armazenamento para os frutos cobertos nas concentrações de 1 e $3 \%$, já os frutos cobertos com a concentração de $2 \%$ de fécula houve uma redução aos 12 dias, enquanto que os frutos que não foram revestidos apresentaram redução do $C^{*}$ a partir dos 9 dias e incremento aos 12 dias, indicando a acentuada diferença de cor nesses frutos que possivelmente houve uma maturação mais rápida (Figura 3). 
Figura 3. Cromaticidade dos frutos de goiaba paluma armazenados sob refrigeração e diferentes concentrações de fécula de mandioca ao longo do tempo de armazenamento.

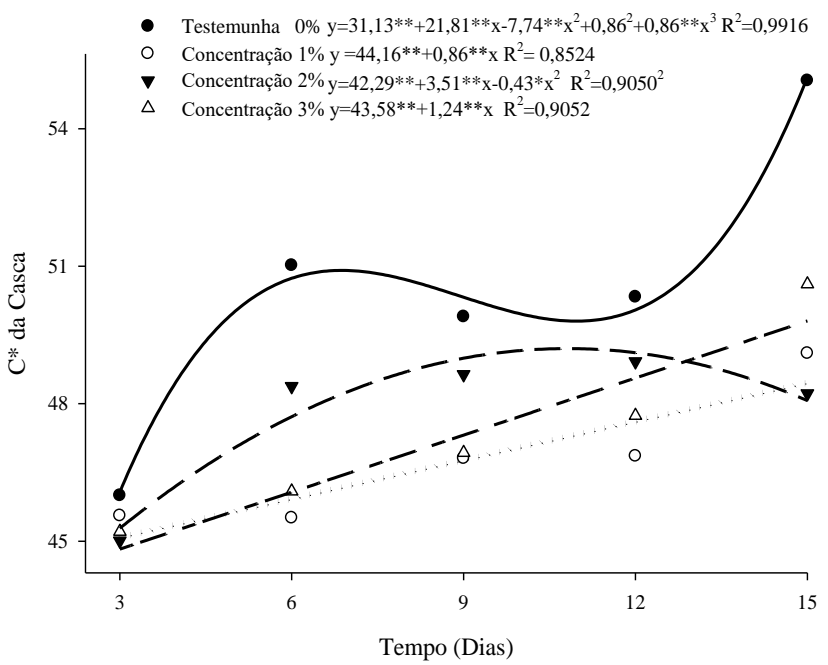

Castricini et al., (2009) observaram durante o período de armazenamento de goiaba, que a elevada taxa de respiração e produção de etileno coincidiram com o amarelecimento do fruto. Dessa forma, a mudança de cor é um indicador natural de maturidade, e essa intensa mudança da coloração da casca nesses frutos pode ter sido ocasionada por um pico na produção de etileno. Rana; Siddiqui; Goyal (2015); Sahoo et al (2015); Aquino et al (2015) e Murmu; Mishra (2017) sintetizaram biofilmes para cobertura em goiabas e obtiveram resultados semelhantes para os parâmetros de cor $\left(\mathrm{C}^{*} \mathrm{e} \mathrm{L}^{*}\right)$, sendo os frutos com cobertura os que apresentaram atividade enzimática reduzida, diminuindo a maturação, e aumentando a vida útil das goiabas.

$\mathrm{O}$ ângulo de cor $\left(\mathrm{h}^{\mathrm{o}}\right)$ expressou significativamente as diferenças de coloração da casca entre os tempos de armazenamento em todos os tratamentos. (Figura 4). Os frutos tratados com revestimento na concentração de $2 \%$ de fécula se encontravam com o ângulo de cor de $119,38^{\circ}$ aos três dias de armazenamento, enquanto que os demais tratamentos, os valores foram de $112^{\circ}$ para os frutos com revestimento na concentração a $1 \%$ de fécula, $110^{\circ}$ para os frutos com revestimento na concentração de $3 \%$ de fécula e $109^{\circ}$ para os frutos sem revestimento de fécula (controle). Os valores do ângulo de cor ao final do armazenamento foram semelhantes para todos os tratamentos, ou seja, independente do uso da cobertura comestível aos 15 dias de avaliação os frutos estavam maduros, contudo a concentração de $2 \%$ de fécula de mandioca retardou o amadurecimento, com os frutos com uma coloração da casca verde aos 11 dias de avaliação..

Os principais processos envolvidos na perda da coloração verde dos frutos durante o amadurecimento são as degradações da clorofila e a síntese dos carotenoides (CROSS, 1987). De acordo com Cardoso (2005), avaliando os parâmetros de ângulo de cor hue para a goiaba "Paluma" encontrou resultados variando de 90,26 a 95,89, resultados bem inferiores encontrados nesse trabalho. Segundo McGuire (1992), valores de $\mathrm{h}^{\circ}$ mais distantes de $90^{\circ}$ representam frutos mais verdes, enquanto que mais próximos de $90^{\circ}$ mais amarelos os frutos.
Figura 4. Ângulo Hue dos frutos de goiaba Paluma armazenados sob refrigeração e diferentes concentrações de fécula de mandioca ao longo do tempo de armazenamento.

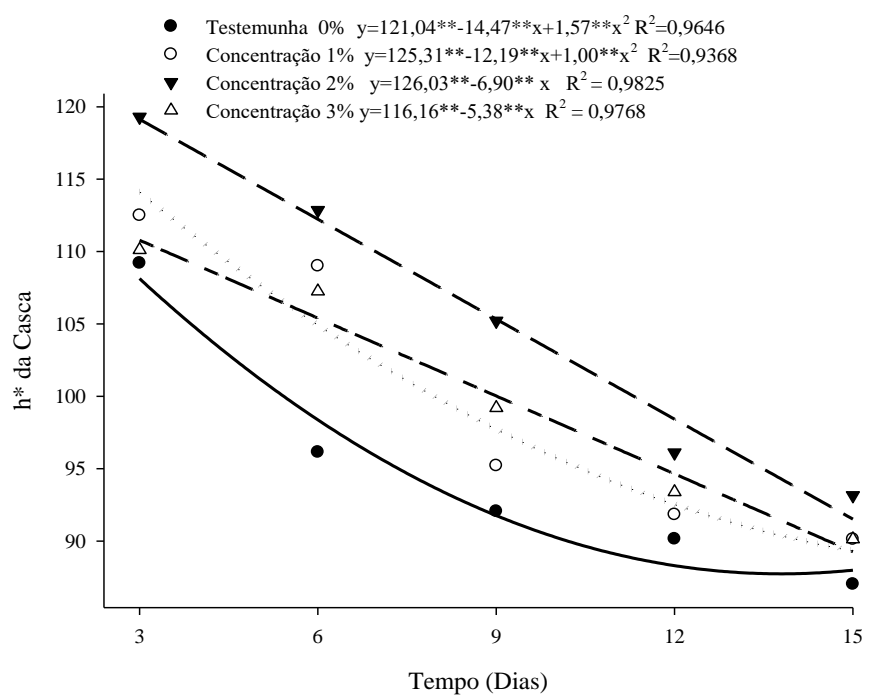

Foi verificado redução no comportamento da firmeza dos frutos ao longo do período de armazenamento em todos os tratamentos, como resultado do amadurecimento (Figura 5). No entanto, verificou-se que os frutos isentos da cobertura comestível à base de fécula de mandioca apresentaram menores valores de firmeza se comparados aos frutos tratados com cobertura, provavelmente a cobertura comestível atuou como barreira física, retardando a perda da firmeza dos frutos. Com o decorrer do período de armazenamento, a cada três dias, houve reduções da firmeza dos frutos equivalentes a 16,$29 ; 11,87 ; 10,37 ; 11,87 \%$ correspondente aos tratamentos controle, concentrações de $1 \%, 2 \%$ e $3 \%$ de fécula de mandioca, respectivamente, demonstrando que a concentração $2 \%$ de fécula apresentou as menores reduções corroborando com a variável de perda de massa.

Figura 5. Firmeza em (N) dos frutos de goiaba Paluma armazenados sob refrigeração e diferentes concentrações de fécula de mandioca ao longo do tempo de armazenamento.

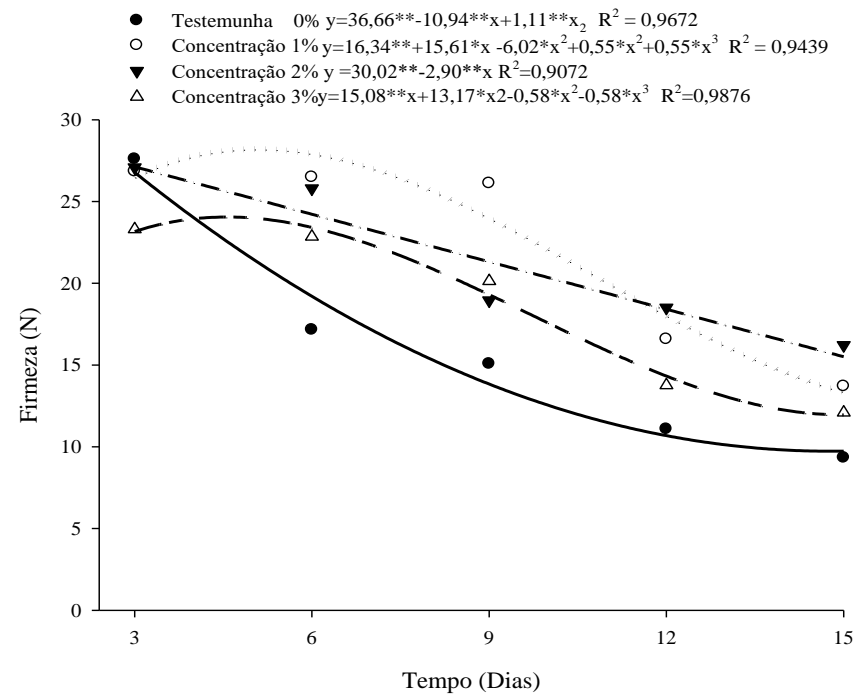

Cavalini (2004) ao estudar a firmeza de polpa de goiabas 'Paluma' encontrou resultados com faixa de $22,44 \mathrm{~N}$ a 14,48 $\mathrm{N}$, valores próximos aos encontrados nesse trabalho $(27,67$ a 10 N). Segundo Botelho et al., (2016), o decréscimo na firmeza, está geralmente associada à ação de enzimas que 
atuam em nível de parede celular, durante o amadurecimento dos frutos.

A acidez em produtos hortícolas é atribuída aos ácidos orgânicos que estão dissolvidos no vacúolo das células e podem variar de acordo com a espécie, sendo que em goiaba predomina o ácido cítrico (CHITARRA; CHITARRA, 2005). Logo, pelos resultados encontrados para acidez titulável observou-se que independe da concentração de fécula houve redução desses teores (Figura 6). No entanto, os frutos sem cobertura comestível (testemunha) apresentaram os maiores valores de acidez durante o período de armazenamento. Os frutos que foram cobertos com a fécula na concentração de $2 \%$ reduziram gradativamente até os 15 dias de avaliação.

Efeito semelhante foi observado por Morgado et al. (2010), onde observaram redução da acidez na polpa de frutos de goiaba armazenados a $21^{\circ} \mathrm{C}$, com um aumento nesse teor quando armazenados sob refrigeração podendo estar atribuído a intensidade do processo de respiração. Na concentração $3 \%$ de fécula de mandioca observou-se uma drástica redução, o qual obteve os menores valores aos seis e nove dias de armazenamento seguido de um leve aumento na acidez aos doze dias, posteriormente houve novamente um decréscimo. Este leve aumento pode ser explicado por Siqueira (2012), quando afirma que o aumento da degradação da parede celular que ocorre durante o armazenamento da goiaba, é responsável por este aumento na concentração de ácidos orgânicos no suco celular.

Figura 6. Acidez titulável em (\%) de ácido cítrico dos frutos de goiaba paluma armazenados sob refrigeração e diferentes concentrações de fécula de mandioca ao longo do tempo de armazenamento.

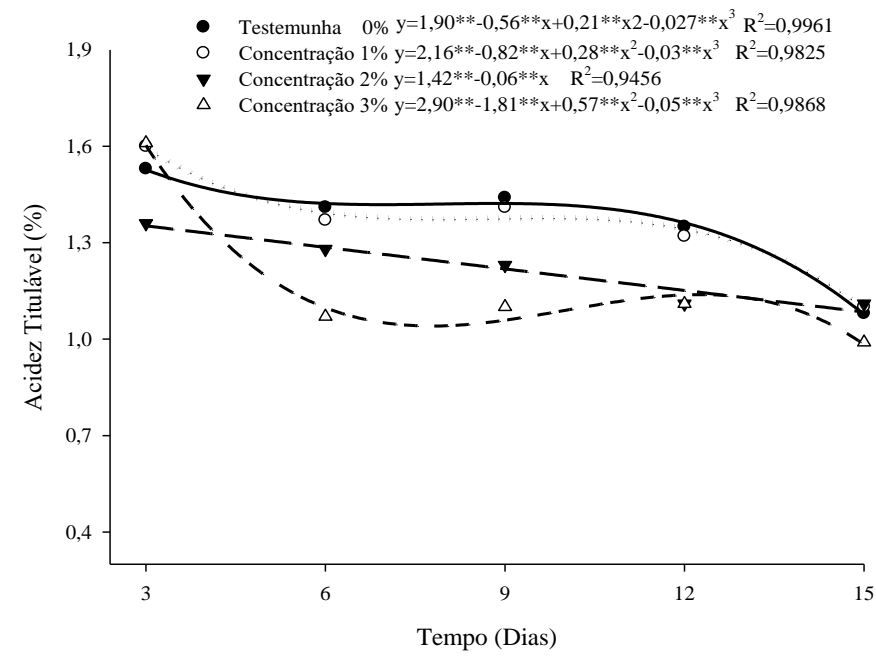

Em relação ao parâmetro sólidos solúveis, observou-se que a testemunha e os frutos cobertos com fécula a $1 \%$ apresentaram comportamento linear crescente, onde estes teores aumentaram a medida que os frutos foram amadurecendo, com maior teor de sólidos solúveis observado nos frutos cobertos na concentração de $1 \%$ de fécula de mandioca aos quinze dias de armazenamento (Figura 7). Os frutos cobertos com fécula nas concentrações de 2 e $3 \%$ apresentaram inicialmente um aumento nestes conteúdos até os nove dias de armazenamento, seguido de pequena redução aos doze dias, atingindo o máximo aos quinze dias de armazenamento. Constatando que o aumento na concentração de fécula retardou o processo de amadurecimento dos frutos.
Figura 7. Teor de sólidos solúveis $\left({ }^{\circ}\right.$ Brix) dos frutos de goiaba paluma armazenados sob refrigeração e diferentes concentrações de fécula de mandioca ao longo do tempo de armazenamento.

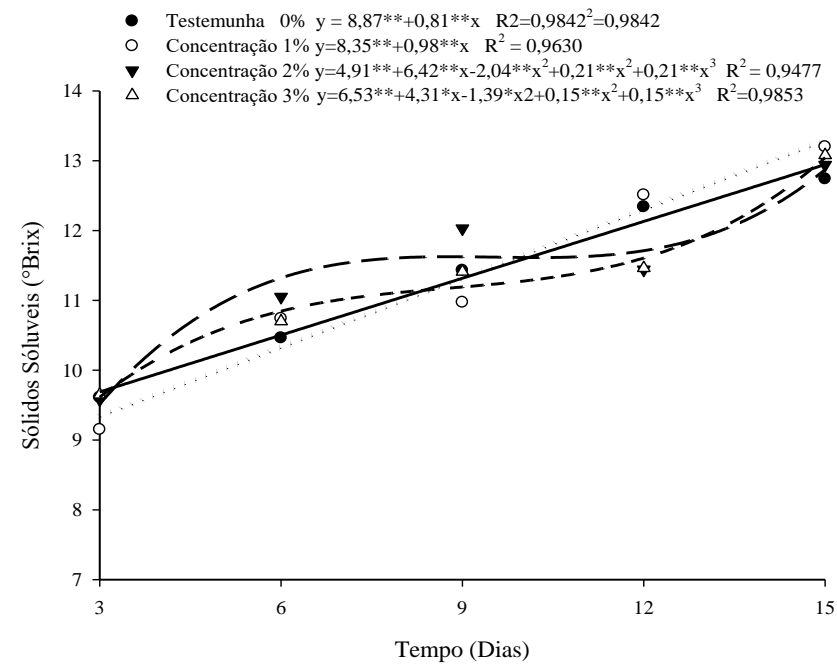

Gomes Filho et al. (2016) observou em frutos de goiabas Pedro Santo na concentração de $3 \%$ de fécula de mandioca associado a extrato de cravo influenciou significativamente nos teores de sólidos solúveis. Segundo Cerqueira et al. (2011) a goiaba é uma espécie que praticamente não armazena amido, no entanto, pequenos incrementos em sólidos solúveis têm sido observados durante o amadurecimento.

A relação sólidos solúveis e acidez titulável apresentaram diminuição em todos os tratamentos ao longo do armazenamento. Os frutos do tratamento na concentração de $3 \%$ de fécula de mandioca apresentaram rápida diminuição nestes teores até os seis dias de armazenamento, mantendo-se estável até os nove dias, posteriormente observou-se leve aumento nestes conteúdos seguido de redução. Comportamento semelhante foi observado para os frutos cobertos com fécula de mandioca na concentração de $1 \%$ (Figura 8).

Figura 8. Relação sólidos solúveis e acidez titulável (SS/AT) dos frutos de goiaba paluma armazenados sob refrigeração e diferentes concentrações de fécula de mandioca ao longo do tempo de armazenamento.

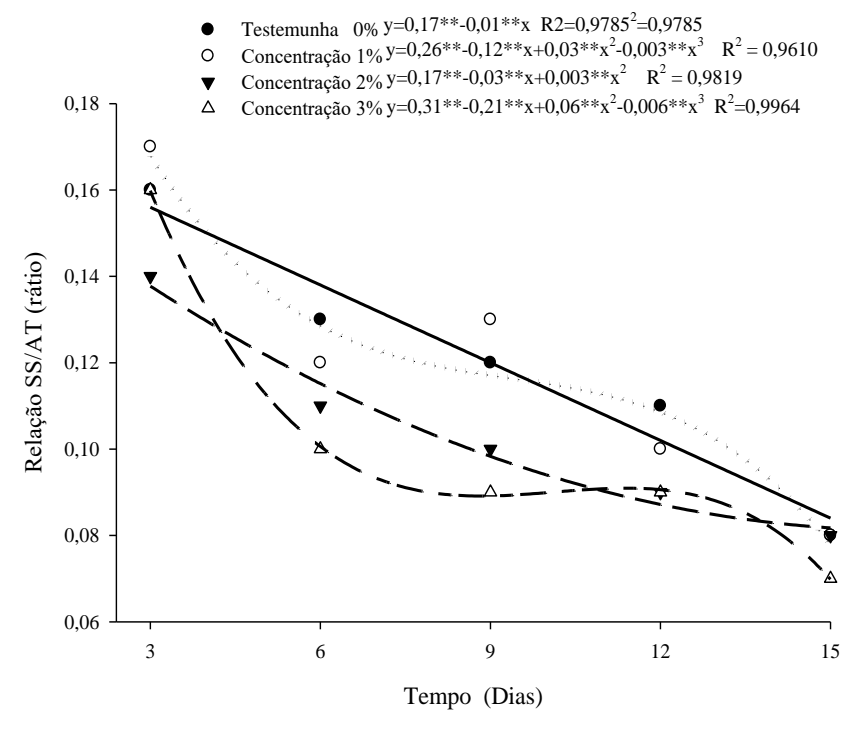


Este leve aumento está relacionado a hidrólise de amido, desidratação dos frutos e degradação de polissacarídeos da parede celular (CHITARRA; CHITARRA 2005). A testemunha e os frutos cobertos com fécula de mandioca a $2 \%$ apresentaram comportamento linear e quadrático respectivamente, atingindo o mínimo valor da relação sólidos solúveis e acidez titulável aos quinze dias de armazenamento.

Verificou-se acréscimo linear nos teores de Vitamina C, durante todo o período em que os frutos ficaram armazenados, indicando assim, síntese dessa vitamina durante o amadurecimento. Os teores de vitamina $\mathrm{C}$ encontrados variaram de 7,85 a $18 \mathrm{mg}$ de ácido ascórbico por $100 \mathrm{~g}^{-1}$ para os frutos controle (sem cobertura comestível), de 11,20 a $22,85 \mathrm{mg}$ de ácido ascórbico por $100 \mathrm{~g}^{-1}$ quando utilizada a cobertura de $1 \%$ de fécula de 15,70 a $23,28 \mathrm{mg}$ de ácido ascórbico por $100 \mathrm{~g}^{-1}$ para os frutos cobertos com $2 \%$ de fécula e de 10,35 a 20,99 mg de ácido ascórbico por $100 \mathrm{~g}^{-1}$ para os com $3 \%$ (Figura 9).

Figura 9. Teor de ácido ascórbico dos frutos de goiaba paluma armazenados sob refrigeração e diferentes concentrações de fécula de mandioca ao longo do tempo de armazenamento.

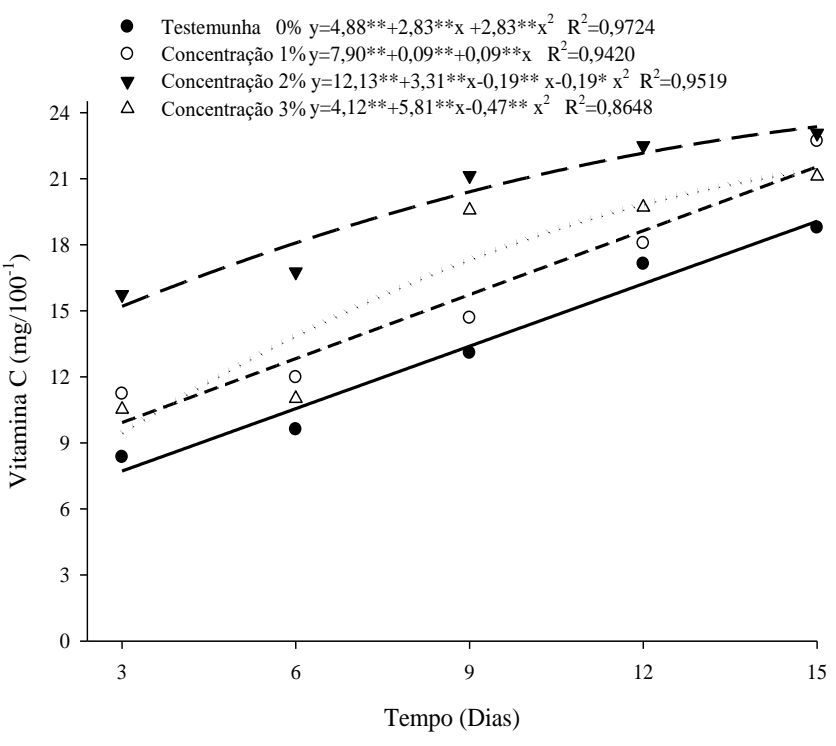

Portanto, os maiores teores de Vitamina $\mathrm{C}$ foram encontrados nos frutos de goiabeira cobertos com $2 \%$ de fécula de mandioca em todos os tempos de armazenamento. Segundo Pereira et al (2005), alguns frutos apresentam aumento no teor de vitamina $\mathrm{C}$, como observado nos frutos de goiabeira (AZZOLINI et al., 2004) ao logo do amadurecimento, devido à um incremento de metabólitos intermediários, que promovem a síntese de glucose-6-fosfato, precursor imediato do ácido ascórbico, desencadeando um aumento do teor de vitamina $\mathrm{C}$ nas fases iniciais, todavia na senescência, os ácidos são oxidados, implicando na redução do teor de ácido ascórbico.

$\mathrm{O}$ pH dos frutos de goiabeira sem cobertura (Testemunha) foi superior aos demais tratamentos, a partir dos 9 dias de armazenamento, ocasionado pela maior taxa de respiração dos frutos em comparação aos frutos revestidos. Por outro lado, ao longo do armazenamento, os valores de $\mathrm{pH}$ oscilaram bastante nos frutos revestidos com 1 e $2 \%$ da fécula de mandioca. Ainda, verificou-se que os frutos cobertos com fécula de mandioca a $3 \%$ decresceu os valores de $\mathrm{pH}$ proporcional ao tempo de armazenamento sendo influenciado pelo decréscimo da acidez titulável (AT). Os dados mostram que os valores de $\mathrm{pH}$, nos tratamentos 1 e $2 \%$ de fécula tendem a aumentar com o amadurecimento da fruta, o que pode ser visualizado entre os dias 9 e 12, contudo menor intensidade que o tratamento controle (Figura 10).

Figura 10. Valores de $\mathrm{pH}$ dos frutos de goiaba Paluma armazenados sob refrigeração e diferentes concentrações de fécula de mandioca ao longo do tempo de armazenamento.

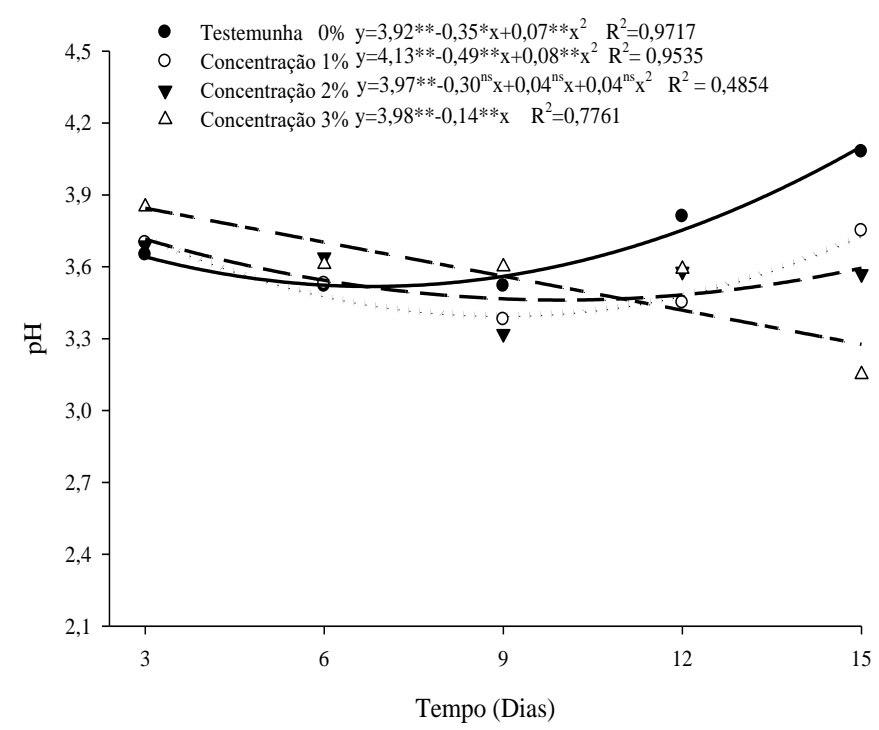

Aquino et al. (2015) verificaram aumento de $\mathrm{pH}$ em goiabas com cobertura de fécula de mandioca e quitosana durante o armazenamento. Essa tendência de consumo de ácidos orgânicos visualizados na AT durante a maturação pode explicar os dados de $\mathrm{pH}$. Essas duas variáveis estão intimamente relacionadas, pois há uma tendência quando a redução ou aumento da acidez, para que haja uma elevação ou diminuição no $\mathrm{pH}$, respectivamente, em decorrência do consumo dos ácidos durante a maturação, o que, possivelmente foi descrito nos dados apresentados (FERNANDES et al., 2010).

\section{CONCLUSÕES}

Os frutos de goiaba paluma armazenados sob refrigeração e diferentes concentrações de fécula de mandioca apresentaram vida útil de 15 dias.

A fécula de mandioca associado com a refrigeração, retardou o amadurecimento dos frutos, principalmente nos frutos revestidos na concentração de $2 \%$ da fécula de mandioca, proporcionando um melhor aspecto e conservação pós-colheita.

\section{REFERÊNCIAS}

ASSIS, O. B. G.; BRITO, D. Revisão: coberturas comestíveis protetoras em frutas: fundamentos e aplicações. Brazilian Journal of Food Technology, v. 17, n. 2, p. 87-97, 2014.

AZZOLINI, M.; JACOMINO, A. P.; SPOTO, M. H. F. Estádios de maturação e qualidade pós-colheita de goiabas 'Pedro Sato'. Revista Brasileira de Fruticultura, Jaboticabal, v.26, n. 1, 2004. 
BESSA, R. A.; OLIVEIRA, L. H.; ARRAES, D. A.; BATISTA, E. S.; NOGUEIRA, D. H.; SILVA, M. S.; RAMOS, P. H. E LOIOLA, A. R. Filmes de Amido e de Amido/Zeólita Aplicados no recobrimento e conservação de goiaba (Psidium guajava). Revista. Virtual Quimica, v. 7. p. 2190-2201. 2015.

CERQUEIRA, T. S.; JACOMINO, A. P.; SASAKI, F. F. E ALLEONI, A. C. C. Recobrimento de goiabas com filmes proteicos e quitosana. Bragantia v.70, p: 216-221. 2011.

CHITARRA, M. I. F.; CHITARRA, A. B. (2005) Póscolheita de frutos e hortaliças: fisiologia e manuseio. $2^{\mathrm{a}}$ ed. Lavras, UFLA. p. 785, 2005.

DURigan, J. F.; MATTIUZ, B. H.; MORGADO, C. M. A. Pós-colheita e processamento mínimo de goiabas. In: NATALE, W.; ROZANE, D. E.; SOUZA, H. A.; AMORIM, A. A. (Org.). Cultura da goiaba: do plantio à comercialização. Jaboticabal: FUNEP, 2009. v.2, p.429-470.

FERREIRA, D. F. Sisvar: a computer statistical analysis system. Ciência e Agrotecnologia (UFLA), v. 35, n.6, p. 1039-1042, 2011.

GOMES FILHO, A. G.; OLIVEIRA, T. F.; OLIVEIRA, S. L.; SILVA, G. G.; CHAGA, L. M. Qualidade pós-colheita de goiabas 'pedro sato' tratadas com diferentes concentrações de fécula de mandioca associadas a substâncias antifúngicas. Revista Agri-Environmental Sciences, Palmas, v. 2, n. 1, 2016.

IBGE. Instituto Brasileiro de Geografia e Estatística. Produção agrícola nacional (2015). Disponível em: <www.ibge.com.br.> Acesso em: 28 de novembro de 2017.

INSTITUTO ADOLFO LUTZ. Métodos físico-químicos para análises de alimentos. São Paulo: Instituto Adolfo Lutz. ed. 4, p. 1020.2008
LUNGUINHO, F. S.; SANTOS, A. F.; BEZERRA, J. M.; VIEIRA, M. M. S. Avaliação não destrutiva na conservação de goiaba 'Paluma' com o uso de embalagens modificadas. Revista Verde, Pombal, v 9, n. 5, p. 40 - 50, dez, 2014.

MORGADO, C. M. A.; DURIGAN, J. F.; LOPES, V. G.; SANTOS, L. O.; Conservação pós-colheita de goiabas 'kumagai': efeito do estádio de maturação e da temperatura de armazenamento. Revista Brasileira de Fruticultura, Jaboticabal - SP, v. 32, n. 4, p. 1001-1008, 2010.

NUNES, A. C. D.; FIGUEIREDO NETO, A.; NASCIMENTO, I. K. S.; OLIVEIRA, F. J. V.; MESQUITA, R. V. C. Armazenamento de mamão 'formosa' revestido à base de fécula de mandioca. Revista de Ciências Agrárias, v.40, n.1, p.254-263, 2017.

PEREIRA, T.; CARLOS, L. A.; OLIVEIRA, J. G.; MONTEIRO, A. R. Influência das condições de armazenamento nas características físicas e químicas de goiaba (Psidium guajava), cv. Cortibel de polpa branca, Revista Ceres, v. 53, p. 276-284, 2006.

PINHEIRO, J. M. S. Tecnologia pós-colheita para a conservação de bananas da cultivar tropical. Dissertação 59p. (Mestrado), Universidade Estadual de Montes Claros, 2009. $59 \mathrm{p}$.

SIQUEIRA, A. M. A.; SANTOS, S. M. L.; LIMA, B. S.; AFONSO, M. R. A.; COSTA, J. C. Vida útil pós-colheita de goiaba cv. 'Paluma' submetida ao resfriamento rápido por ar forçado. Revista Ciência Agronômica, v. 45, n. 1, p. 45-51, jan-mar, 2014.

SIQUEIRA, A. P. O. Uso de coberturas comestíveis na conservação pós colheita de goiaba e maracujá-azedo. Dissertação 91p. (Mestrado em Produção Vegetal)Universidade Estadual do Norte Fluminense. Campos dos Goytacazes, 2012. 